\title{
Epidemiology and treatment of gonorrhoea caused by penicillinase-producing strains of Neisseria gonorrhoeae in Fukuoka, Japan
}

\author{
SHINJI URABE, ${ }^{*}$ SHIN-ICHI YOSHIDA, + AND YASUO MIZUGUCHI† \\ From *Urabe Hospital, Nishi-Nakasu, Fukuoka, and the +Department of Microbiology, School of \\ Medicine, University of Occupational and Environmental Health, Kitakyushu, Japan
}

SUMMARY Thirty strains of penicillinase-producing Neisseria gonorrhoeae(PPNG) were detected by a rapid iodometric method out of 206 strains isolated from patients with gonorrhoea between January and December 1981 . Of the 30 patients, five of the nine women were prostitutes and 14 of the 21 men were infected by prostitutes in or around Fukuoka City, with the exception of one who was infected in Formosa. Treatment with ampicillin or amoxycillin resulted in failure whereas treatment with spectinomycin was successful.

\section{Introduction}

Penicillinase-producing Neisseria gonorrhoeae (PPNG) strains were isolated for the first time in 1976 in the United Kingdom ${ }^{1-3}$ and in the United States ${ }^{4}$ and since have been found in many countries all over the world. ${ }^{5}$ Although we reported the antibiotic sensitivity patterns of 25 PPNG strains and 130 non-PPNG strains isolated in Fukuoka, Japan, in $1981^{6}$ the epidemiology of PPNG strains in Japan has not been reported. In the present study we determined the epidemiology and results of treatment in 30 patients with gonorrhoea due to PPNG strains who attended Urabe Hospital, Fukuoka City, Japan, in 1981.

\section{Patients and methods}

All the isolates of penicillinase-producing $N$ gonorrhoeae (PPNG) were obtained from patients attending Urabe Hospital between January and December 1981. They were identified by Gram-stained microscopy, the oxidase reaction, and their ability to produce acid from glucose but not from lactose, maltose, and sucrose (tested by the Minitek System, BBL). Their ability to reduce nitrate was also determined. The production of $\beta$-lactamase by gonococcal isolates was examined by a rapid iodometric method.?

Address for reprints: Dr S Yoshida, Department of Microbiology, School of Medicine, University of Occupational and Environmental Health, Kitakyushu, 807 Japan

Accepted for publication 9 August 1982
The sensitivity of PPNG strains to penicillin G, amoxycillin, doxycycline, and spectinomycin was determined by the agar dilution method. ${ }^{6}$

Gonorrhoea was treated with four drug regimens as summarised in table I. The results of treatment were evaluated by the following criteria:

Cure-Diplococci were absent in Gram-stained smears, and follow-up cultures gave negative results. When more than 10 pus cells per high power field $(\times 100$ objective) were found in the urethral smear, postgonococcal urethritis (PGU) was considered to be present. In the case of female patients postgonococcal cervicitis (PGC) was also noted.

Failure-Diplococci were present in Gram-stained smears or follow-up culture for $N$ gonorrhoeae gave a positive result.

TABLE I Treatment schedules for gonorrhoea

\begin{tabular}{llll}
\hline Drug & Dose/day & Route & $\begin{array}{l}\text { Duration of } \\
\text { ireatment } \\
\text { (days) }\end{array}$ \\
\hline Ampicillin & $1.5 \mathrm{~g}$ & Oral & $3-7$ \\
Amoxycillin & $1.0 \mathrm{~g}$ & Oral & $3-7$ \\
Doxycycline & $200 \mathrm{mg}$ & Oral & $3-7$ \\
Spectinomycin & $2.0 \mathrm{~g}$ & Intramuscular & Single dose \\
\hline
\end{tabular}

*All patients were required to return within three to four days for follow-up.

\section{Results}

EPIDEMIOLOGY

Of 206 isolates of $N$ gonorrhoeae, $30(14 \cdot 6 \%)$

produced penicillinase. The epidemiology of 
gonorrhoea due to PPNG strains is summarised in table II. Of the 30 patients, 21 were men and nine women; five of the nine women were prostitutes, and 14 of 21 infections in men were acquired from prostitutes. With one exception (case No 8), a man who had been infected in Formosa, the men were infected in or around Fukuoka City. The incidence of infection due to PPNG strains was relatively high in September and December. Five pairs of patients were related epidemiologically.

TABLE II Epidemiological data of patients harbouring PPNG strains isolated in Fukuoka (1981)

\begin{tabular}{|c|c|c|c|c|c|}
\hline Month & $\begin{array}{l}\text { Case } \\
\text { No* }\end{array}$ & $\begin{array}{l}\text { Age } \\
\text { (years) }\end{array}$ & Sex & Occupation & Source \\
\hline \multirow[t]{2}{*}{ March } & 1 & 18 & F & Prostitute & \\
\hline & 2 & 22 & M & & Common-law wife \\
\hline \multirow[t]{2}{*}{ April } & 3 & 21 & M & & Girlfriend \\
\hline & 4 & 26 & $\mathbf{M}$ & & Prostitute \\
\hline \multirow[t]{2}{*}{ May } & 5 & 45 & $\mathrm{M}$ & & Prostitute \\
\hline & 6 & 39 & $\mathrm{~F}$ & & Boyfriend \\
\hline \multirow[t]{3}{*}{ July } & 7 & 27 & $\mathrm{M}$ & & Prostitute \\
\hline & 8 & 48 & $\mathbf{M}$ & & Prostitute \\
\hline & 9 & 33 & $\mathbf{M}$ & & Prostitute \\
\hline \multirow[t]{2}{*}{ August } & 10 & 25 & M & & Prostitute \\
\hline & 11 & 24 & $\mathrm{M}$ & & Prostitute \\
\hline \multirow[t]{6}{*}{ September } & 12 & 22 & $\mathrm{~F}$ & Prostitute & \\
\hline & 13 & 20 & $\mathbf{F}$ & Prostitute & \\
\hline & 14 & 20 & $\mathrm{~F}$ & Prostitute & \\
\hline & 15 & 21 & $\mathbf{M}$ & & Common-law wife \\
\hline & 16 & 28 & $\mathbf{F}$ & & Husband \\
\hline & 17 & 33 & $\mathbf{M}$ & & Prostitute \\
\hline \multirow[t]{3}{*}{ October } & 18 & 31 & M & & Girlfriend \\
\hline & 19 & 28 & M & & Prostitute \\
\hline & 20 & 27 & $\mathbf{M}$ & & Bar girl \\
\hline \multirow[t]{2}{*}{ November } & 21 & 26 & $\mathbf{M}$ & & Bar girl \\
\hline & $\begin{array}{l}22 \\
23\end{array}$ & $\begin{array}{l}27 \\
21\end{array}$ & $\begin{array}{l}\mathbf{M} \\
\mathbf{M}\end{array}$ & & $\stackrel{?}{\text { Girlfriend }}$ \\
\hline \multirow[t]{6}{*}{ December } & 24 & 32 & M & & Prostitute \\
\hline & 25 & 22 & $\mathbf{F}$ & & Boyfriend \\
\hline & 26 & 28 & $\mathbf{M}$ & & Prostitute \\
\hline & 27 & 27 & $\mathbf{F}$ & Prostitute & \\
\hline & $\begin{array}{l}28 \\
20\end{array}$ & & $\mathbf{F}$ & & Husband \\
\hline & $\begin{array}{l}29 \\
30\end{array}$ & $\begin{array}{l}24 \\
28\end{array}$ & $\begin{array}{l}M \\
M\end{array}$ & & $\begin{array}{l}\text { Prostitute } \\
\text { Girlfriend }\end{array}$ \\
\hline
\end{tabular}

*Patients in case Nos 1 and 2, 5 and 6,14 and 15, 16 and 17, 28 and 29 were epidemiologically related

\section{MINIMUM INHIBITORY CONCENTRATIONS}

The distributions of minimum inhibitory concentrations (MICs) of penicillin G, amoxycillin, doxycycline, and spectinomycin for each gonococcal strain are shown in table III. As we reported previously ${ }^{6}$ MICs for PPNG strains of penicillin G, amoxycillin, or doxycycline were very high compared with those for non-PPNG strains. All the isolates were sensitive to spectinomycin.

\section{TREATMENT AND FOLLOW-UP}

Treatment and the results of follow-up of each patient are shown in table III and the cumulative data summarised in table IV. Initial treatment with ampicillin of six of seven patients and with amoxycillin of all of 16 patients resulted in failure; one patient who was cured with ampicillin was a prostitute (case No 12), but postgonococcal urethritis and cervicitis developed. Of the 28 patients treated with $\Rightarrow$ spectinomycin, eight did not return for follow-up. In $\stackrel{5}{\rightarrow}$ 19 of 20 cases who were available for follow-up the treatment was successful; treatment of one patient, a 흠 prostitute (case No 14), was not successful. The $\frac{5}{\vec{D}}$ incidence of PGU after treatment with spectinomycin $\triangle$

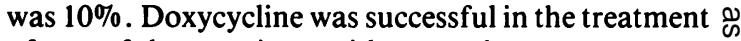
of two of three patients with gonorrhoea.

\section{Discussion}

Our present study shows that PPNG strains are $\stackrel{\frac{0}{9}}{=}$ becoming an increasing problem in Fukuoka, Japan. (f Thirty $(14 \cdot 6 \%)$ out of 206 isolates produced $\vec{\omega}$ penicillinase. Furthermore, these PPNG strains $\underset{v}{\omega}$ appear to have established themselves in the local 음 population, mainly among prostitutes. The role of prostitutes in the spread of PPNG strains has been 7 stressed previously ${ }^{8}$ and has been confirmed by our $\frac{\mathbb{O}}{2}$ data on the source of infection. Importation of PPNG strains from other countries no longer plays a major role in the spread of PPNG strains in our patients.

Almost all patients treated with ampicillin or $\underset{\omega}{\infty}$ amoxycillin were not cured; spectinomycin was the only drug that produced acceptable cure rates. Spectinomycin was successful in the treatment of gonorrhoea caused by both non-PPNG ${ }^{10}$ and PPNG $^{8}$ व strains. The Center for Disease Control (Atlanta, Georgia, USA) ${ }^{112}$ also recommend spectinomycin as first-line treatment. Our in-vitro susceptibility tests showed that all PPNG isolates were sensitive to spectinomycin, and spectinomycin $2 \mathrm{~g}$ intramuscularly proved to be effective in the treatment of 27 of 28 patients.

The default rate of $28 \cdot 6 \%$ illustrates the importance of treatment that will be rapidly successful. It is probable that patients who did not return for follow- of up were cured. Treatment failure occurred in one $₹$

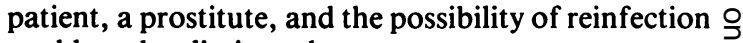
could not be eliminated.

Although doxycycline was successful in the treatment of two of three patients its efficacy cannot be evaluated in only a few cases. As indicated $O$ previously ${ }^{6}$ the MICs of doxycycline for PPNG strains $N$ were appreciably higher than for non-PPNG strains. N Nayyar et $a l^{8}$ also reported that PPNG strains seemed to be less sensitive to tetracycline than non-PPNG 0 strains isolated in Rotterdam. Further evaluation of $\underset{\mathbb{D}}{\stackrel{\mathrm{D}}{2}}$ tetracycline in the treatment of gonorrhoea caused by PPNG strains is needed.

Because of the urgent need for alternative treatment for patients infected with PPNG strains $\beta$-lactamaseresistant cephalosporins or cefamycins have been used recently. Cefotaxime, ${ }^{1314}$ cefuroxime, ${ }^{1516}$ and 


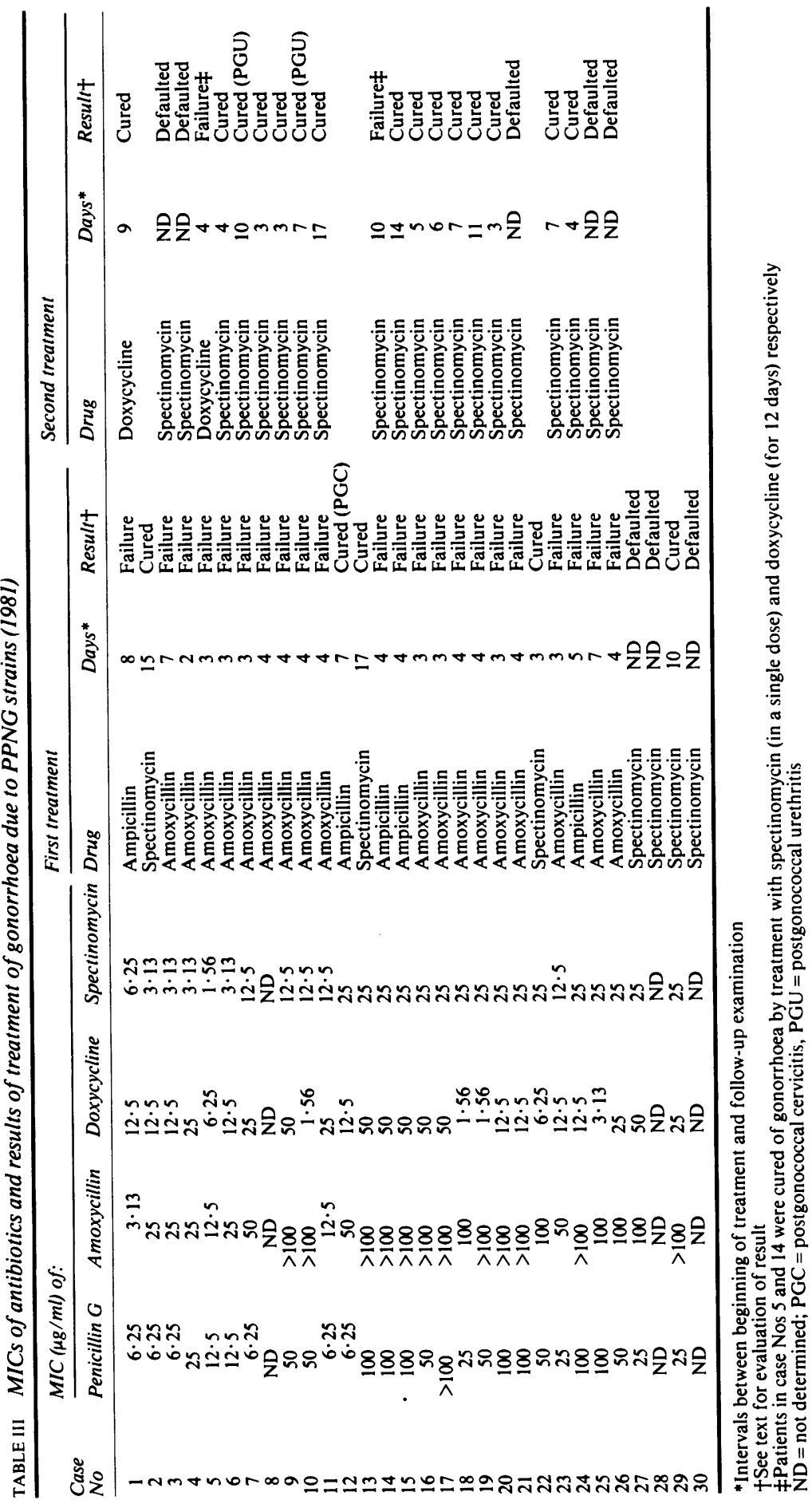


TABLE IV Cumulative data on the results of treatment of 30 patients with gonorrhoea due to PPNG strains

\begin{tabular}{llllll}
\hline & $\begin{array}{l}\text { Total } \\
\text { No } \\
\text { of }\end{array}$ & \multicolumn{4}{c}{ Results of follow-up* } \\
\cline { 3 - 6 } & of case & Cure & PGU/C+ & Failure & Defaulted \\
\hline Ampicillin & 7 & 1 & 1 & 6 & 0 \\
Amoxycillin & 16 & 0 & 0 & 16 & 0 \\
Doxycycline & 3 & 2 & 0 & 1 & 0 \\
Spectinomycin & 28 & 19 & 2 & 1 & 8 \\
\hline
\end{tabular}

*See text for evaluation of results

†Postgonococcal urethritis/cervicitis

cefoxitin ${ }^{17}$ have proved to be very successful in the treatment of gonorrhoea due to PPNG strains.

As suggested by $\mathrm{Thin}^{18}$ careful follow-up and rapid and vigorous contact tracing are essential also in the Fukuoka area. Sng et al $^{19}$ advised that it would be prudent to screen all gonococcal isolates for $\beta$-lactamase in an area where the prevalence of PPNG is $1 \%$ or more. Recently, rapid and simple methods for the detection of $\beta$-lactamase production have been available commercially. Such tests should be available for both hospital and clinic use.

\section{References}

1. Phillips I. $\beta$-lactamase-producing, penicillin-resistant gonococcus. Lancet 1976;ii:656-7.

2. Percival A, Rowlands J, Corkill JE, et al. Penicillinaseproducing gonococci in Liverpool. Lancet 1976;ii:1379-82.

3. Perine PL, Thornsberry C, Schalla W, et al. Evidence for two distinct types of penicillinase-producing Neisseria gonorrhoeae. Lancet 1977;ii:993-5.
4. Ashford WA, Golash RG, Hemming VG. Penicillinaseproducing Neisseria gonorrhoeae. Lancet 1976; ii:657-8.

5. Center for Disease Control. Global distribution of penicillinaseproducing Neisseria gonorrhoeae (PPNG). Morbid Mortal $\vec{F}$ Weekly Rep 1982;31:1-3.

6. Yoshida S, Urabe S, Mizuguchi Y. Antibiotic sensitivity patterns of penicillinase-positive and penicillinase-negative strains of Neisseria gonorrhoeae isolated in Fukuoka, Japan. $\mathrm{Br} J$ Vener Dis 1982;58:305-7.

7. Anonymous. Neisseria gonorrhoeae producing penicillinase. Wkly Epidem Rec 1976;51:293-4.

8. Nayyar KC, Noble RC, Michel MF, Stolz E. Gonorrhoea in Rotterdam caused by penicillinase-producing gonococci. $\mathrm{Br} \mathrm{J} \mathrm{C}$ Vener Dis 1980;56:244-8.

9. Finger AH. Spectinomycin in the treatment of gonorrhoea in $\vec{O}$ females and males. Br J Vener Dis 1975;51:38-40.

10. Grunder K, Petzoldt D. Sensitivity of Neisseria gonorrhoeae to $\vec{\omega}$ spectinomycin and thiamphenicol. BrJ Vener Dis 1980;56:252-4. ఠ)

11. Center for Disease Control. Gonorrhea: CDC-recommended 0 treatment schedules, 1979. J Infect Dis 1979;139:496-501.

12. McCormack WM. Treatment of gonorrhea. Ann Intern Med of 1979;90:845-6.

13. Rajan VS, Sng EH, Pang R, Tan NJ, Thirumoorthy T, Yeo KL. HR756 - a new cephalosporin in the treatment of gonorrhoea $\underset{V}{ }$ caused by ordinary and penicillinase-producing strains of 0 Neisseria gonorrhoeae. Br J Vener Dis 1980;56:255-8.

14. Slack RC, Bittiner JB, Finch R. Treatment of gonorrhoea caused by $\beta$-lactamase-producing strains of Neisseria gonorrhoeae with cefotaxime. Lancet 1980; i:431-2.

15. Nayyar KC, Michel MF, Stolz E. Antibiotic sensitivities of gonococci isolated in Rotterdam and results of treatment with cefuroxime. BrJ Vener Dis 1980;56:249-51.

16. Normark S, Elmros T, Norlander L, et al. Cefuroxime treatment of urethritis caused by $\beta$-lactamase-producing strain of Neisseria gonorrhoeae. Acta Derm Venereol (Stockh) 1980;60:277-9.

17. Berg SW, Kilpatrick ME, Harrison WO, McCutchan JA. Cefoxitin as a single-dose treatment for urethritis caused by penicillinase-producing Neisseria gonorrhoeae. N Engl J Med 1979;301:509-11.

18. Thin RN. Gonorrhoea: a continuing problem in the 1980s. $\mathrm{Br} J$ Vener Dis 1980;56:193.

19. Sng EH, Yeo KL, Rajan VS, Lim AL. Comparison of methods for the detection of penicillinase-producing Neisseria gonorrhoeae. Br J Vener Dis 1980;56:311-3. 